\title{
Goodwill message from the Vice Chancellor
}

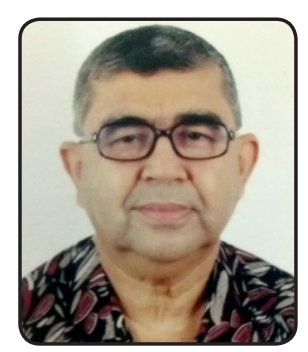

It gives me great pleasure to know that Pokhara Academy of Health Sciences, (PAHS) has come out with its first publication of medical journal of Pokhara Academy of Health Sciences (MJPAHS). This can be a beginning of implementation of the policy of federal Government of Nepal to set at least one government medical college in each province. PAHS has been established in the year 2016(2072 B.S) with an aim to begin postgraduate medical education in province number 4 and provide quality care and affordable medical service to all, in general, poor and marginalized people in particular. It also aims to carry out scientific research and study in different health related areas of this region. Accordingly we have formed IRC, Medical Education Department and Journal Editorial Board to carry out all its activities. This journal publication has been possible only because of collaborative, cooperative and untiring efforts of editorial board. I congratulate Dr. Bhogendra Bahadur KC and all other members of Editorial Board for this great job. I am sure this journal will fulfil the academic needs of all faculties and students and academics of different health institutes of this region.

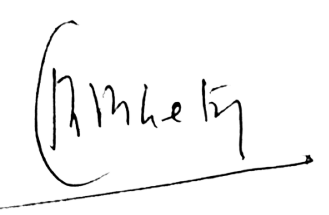

Prof. Dr. Buddhi Bahadur Thapa

Vice- Chancellor

Pokhara Academy of Health Sciences

Pokhara, Nepal 